\title{
Comparação de custos de implantação de eucalipto com resíduo celulósico em substituição ao fertilizante mineral ${ }^{1}$
}

\author{
Otton Garcia de Arruda², Maria Aparecida Anselmo Tarsitano ${ }^{3}$, Marlene Cristina Alves ${ }^{4}$, \\ Rômulo Guimarães Giácomo 5
}

\section{RESUMO}

A grande expansão das indústrias e do mercado consumidor tem provocado, nas últimas décadas, a geração de elevadas quantidades de resíduos, os quais têm constituído constante preocupação econômica e ambiental. Objetivouse, neste trabalho, analisar a viabilidade econômica do uso de três doses de composto orgânico, oriundo da compostagem de resíduos da extração da celulose, em substituição à adubação mineral, na cultura do eucalipto, no município de Selvíria, MS. A metodologia de custos adotada foi a do custo operacional total e do custo total. Concluiuse que, por causa do elevado custo de transporte e aplicação, a adubação orgânica mostrou-se mais onerosa em relação à mineral, sendo sua utilização viável, economicamente, apenas nas proximidades da indústria produtora.

Palavras-chave: Eucaliptus urograndis, custo de implantação, composto celulósico, adubação.

\section{ABSTRACT \\ Comparison between the costs of substituting mineral fertilization with eucalyptus cellulose residues}

The expanded growth of the paper and cellulose industry and the consumer market in recent decades has led the production of large amounts of waste, which has become a major economic and environmental concern. The aim of this study was to evaluate the economic feasibility of using three rates of organic compost derived from composted cellulose extraction residues to replace mineral fertilizers in eucalyptus cultivation, in Selvíria, MS, Brazil. The cost methodology was based on the total operational cost and total cost. The organic fertilization was more expensive than the mineral fertilization due to the high costs of transportation and application, being economically viable only in areas close to the industries.

Key words: Cellulose residue, Eucalyptus urograndis, fertilization, substitution cost.

\footnotetext{
Recebido para publicação em 21/03/2011 e aprovado em 19/09/2011

${ }^{1}$ Trabalho parte da dissertação de mestrado do primeiro autor. Financiado pela Fapesp.

Engenheiro-Agrônomo. Universidade Estadual Paulista, Avenida Brasil, 56, 15385-000, Ilha Solteira, São Paulo, Brasil. otton.garcia@gmail.com.

Engenheira-Agrônoma, Doutora. Departamento de Fitotecnia, Tecnologia de Alimentos e Socio-economia, Universidade Estadual Paulista, Avenida Brasil, 56, 15385-000, Ilha Solteira, São Paulo, Brasil. maat@agr.feis.unesp.br

${ }^{4}$ Engenheira-Agrônoma, Doutora. Departamento de Fitossanidade, Engenharia Rural e Solos, Universidade Estadual Paulista, Avenida Brasil, 56, 15385-000, Ilha Solteira, São Paulo, Brasil. mcalves@agr.feis.unesp.br

5ngenheiro Florestal, Mestre. Universidade Estadual Paulista, Avenida Brasil, 56, 15385-000, Ilha Solteira, São Paulo, Brasil. romuloflorestal@gmail.com
} 


\section{INTRODUÇÃO}

O Brasil possui área total de, aproximadamente, 8.514.877 km² (851,4 milhões de hectares). Deste total, 477,7 milhões de ha correspondem a florestas naturais e 5,98 milhões de ha a florestas plantadas. Deste total, 3,75 milhões correspondem a áreas com eucalipto; 1,80 milhões com Pinus e 425,2 mil com outras espécies, ocupando apenas 0,7 do território nacional (SBS, 2008).

Os produtos de origem florestal figuram entre os 10 principais produtos comercializados, internacionalmente, com $3 \%$ do comércio global, cerca de US\$ 300 bilhões. O setor de base florestal brasileiro tem participação significativa no Produto Interno Bruto nacional (US\$ 1,3 trilhão), representando 3,4\% do PIB nacional, ou seja, US\$ 44,6 bilhões. As exportações brasileiras alcançaram US\$160,65 bilhões, em 2007, representando um crescimento de 17\%, em relação ao ano anterior. O segmento de celulose e papel teve maior participação nas exportações brasileiras de produtos florestais, com US $\$ 4,7$ bilhões e um crescimento de $18,0 \%$, em relação ao ano de 2006 (US $\$ 4,0$ bilhões). As exportações de madeira representaram cerca de US\$ 3,3 bilhões; as de móveis, US\$ 994,3 milhões e as de carvão vegetal, US\$ 600 mil. (SBS, 2008).

Por causa dos efeitos da crise mundial, o setor florestal operou abaixo de sua capacidade de produção e com as exportações em queda, até meados de 2009, quando o segmento de celulose e papel retomou o crescimento da produção, após o início das atividades de novas fábricas e aumento da demanda para exportação (SBS, 2009). Segundo a Associação Brasileira de Celulose e Papel (BRACELPA), em 2009, a produção de celulose somou 13,41 milhões de toneladas, superando em $6,0 \%$ o ano de 2008. Em relação à produção de papéis, a recuperação deu-se de forma mais lenta, atingindo 9,34 milhões de $\mathrm{t}$ (estável em relação a 2008). As exportações de celulose cresceram $16,9 \%$, em volume, e, as de papel, $3 \%$. Porém, as receitas, que totalizaram US\$ 5,0 bilhões (-14,3\% em relação a 2008), não se recuperaram, em função do câmbio e dos preços internacionais.

Para atender à demanda mundial de papel, a indústria de celulose vem obtendo incrementos expressivos de produção, o que faz que haja aumento da demanda de matéria-prima. A necessidade de aumento de produção tem feito que as empresas do setor busquem alternativas de manejo que aumentem a produtividade florestal (Almeida, 2008), dentre as quais, uma prática alternativa, que tem sido avaliada, é a utilização de compostos provenientes de resíduos da extração da celulose.

Nos processos industriais que envolvem a madeira, usualmente são gerados resíduos com alto percentual de matéria orgânica, como a casca, a lama cal, o lodo ativado, dregs, grits e a cinza de caldeira da queima de biomassa, sendo, portanto, as sobras que ocorrem no processamento mecânico, físico ou químico e que não são incorporados ao produto final. O processo químico mais empregado para a produção de celulose de eucalipto é o "Kraft", que utiliza sulfeto de hidróxido de sódio como agente químico ativo (Bellote et al., 1998; Barretto, 2008).

A lama cal é formada, predominantemente, por carbonato de cálcio e os dregs são sedimentos sólidos alcalinos, de cor escura e odor característico, removidos no processo de clarificação das impurezas, sendo composto por carbono não queimado, ferro, sílica, cálcio, alumina, magnésio e sulfetos. Grits são os resíduos sólidos granulados, resultantes do processo de calcinação da lama cal e do calcário, nos fornos (Barretto, 2008; Albuquerque et al., 2002).

As fábricas de papel e celulose geram em torno de 48 t de resíduos, para cada 100 t de celulose produzida, e deparam-se com problemas de ordem ambiental, quanto à destinação desses resíduos (Bellote et al., 1998). Diversos trabalhos de investigação têm sido realizados no sentido de buscar soluções para utilização desses resíduos, permitindo o seu aproveitamento e a diminuição do impacto ambiental (Bellote et al., 1998; Andrade et al., 2003; Rodrigues, 2004).

Dentre as soluções preconizadas, a compostagem posiciona-se como uma alternativa viável, por seu baixo custo e sua simplicidade, em termos tecnológicos, permitindo, também, a obtenção de fertilizantes orgânicos naturais, os quais contribuem para a melhoria das propriedades físicas, químicas e biológicas do solo, influenciando diretamente no desenvolvimento das espécies ali plantadas (Guerrini \& Moro, 1994; Andrade et al., 2003; Guerra, 2007).

Bellote et al. (1998), estudando os resíduos da indústria de celulose em plantios florestais, observaram os seguintes efeitos benéficos no solo: elevação do $\mathrm{pH}$, com consequente aumento na disponibilidade de determinados nutrientes, notadamente fósforo e micronutrientes; aumento da capacidade de troca de cátions dos solos; incorporação de nutrientes minerais necessários às árvores; melhoria das propriedades físicas, como a granulometria, a capacidade de retenção de água e a densidade do solo. Além disso, a aplicação de resíduos da celulose e de cinza de caldeiras aumenta a atividade biológica do solo, acelerando a decomposição da serapilheira e a ciclagem de nutrientes.

Guerrini \& Moro (1994) concluíram que os teores observados de certos nutrientes com a aplicação de resíduo celulósico são semelhantes, ou, até, superiores, aos fornecidos pela adubação química, especialmente no caso do cálcio. Dependendo da dose, tipo de resíduo e época de aplicação, é possível a substituição completa dos fertilizantes químicos pelos resíduos orgânicos. 
Com base nesses argumentos, objetivou-se, neste trabalho, analisar economicamente a implantação da cultura do eucalipto com uso de composto, oriundo de resíduos da indústria de celulose, em substituição ao fertilizante químico.

\section{MATERIAL E MÉTODOS}

O experimento foi implantado na Fazenda de Ensino e Pesquisa, da Faculdade de Engenharia, Campus de Ilha Solteira (UNESP), localizada no município de Selvíria, MS, à margem direita do Rio Paraná, nas coordenadas geográficas de $51^{\circ} 22^{\prime} \mathrm{O}$ e $20^{\circ} 22^{\prime} \mathrm{S}$, a $327 \mathrm{~m}$ de altitude, com médias anuais de: precipitação pluvial, $1.370 \mathrm{~mm}$; temperatura, $23,5^{\circ} \mathrm{C}$; e umidade relativa do ar, entre 70 e $80 \%$ (Demattê,1980). O clima da região, classificado de acordo com o Sistema Internacional de Köeppen, é o tropical úmido Aw, com estação chuvosa no verão e seca no inverno. A vegetação nativa da região de estudo era o Cerrado, o relevo é de suave a plano e o solo original é um Latossolo Vermelho distrófico (Demattê, 1980; Embrapa, 2006), muito profundo, de textura franco- argilo-arenosa.

O levantamento dos dados, para análise técnica e econômica, foi realizado em uma área experimental de $4320 \mathrm{~m}^{2}$, implantada no ano de 2010 com o híbrido Eucalyptus urograndis, clone "H-17" (eucalipto - exótico), com espaçamento de $3 \times 2 \mathrm{~m}$, disposto com delineamento em blocos casualizados. Os dados foram obtidos mediante registro das operações realizadas e insumos utilizados, com os seus respectivos coeficientes técnicos.

Assim, tornou-se possível a elaboração de planilhas para comparar o custo da adubação química e o da utilização do composto celulósico, em diferentes doses (10 t ha ${ }^{-1}$, $15 \mathrm{t} \mathrm{ha}^{-1}$ e $20 \mathrm{t} \mathrm{ha}^{-1}$ do composto), visando à substituição do uso de fertilizantes, por resíduos industriais, no plantio do eucalipto.

O método utilizado para elaboração dessas planilhas baseia-se no Custo Operacional Total (COT), utilizado pelo Instituto de Economia Agrícola (IEA) e proposto por Matsunaga et al. (1976), que permite obter o Custo Operacional Efetivo (COE), que se constitui da soma das despesas diretas de custeio. Acrescentando-se ao $\mathrm{COE}$ outras despesas, as depreciações e juros de custeio, obtém-se o COT. Foi considerada a taxa de $6,75 \%$ a.a., sobre a metade do Custo Operacional Efetivo (COE), como juros de custeio de 5\% a.a. sobre o COE como outras despesas. A depreciação de máquinas e implementos foi estimada pelo método linear, determinado pelo valor inicial menos o valor final, dividido pela vida útil, valores obtidos pela CONAB (2010). A remuneração da terra foi calculada de acordo com o valor do arrendamento da terra na região, e outros custos fixos, como $5 \%$ sobre a metade do COE (Martin et al., 1998).
A recomendação de adubação mineral da cultura do eucalipto foi realizada a partir do resultado da análise de solo (Tabela 1) e, segundo Raij et al. (1997), pôde-se determinar a quantidade de nutrientes a serem aplicados, sendo que, para a obtenção de produtividades elevadas, foi necessária a aplicação de $40 \mathrm{~kg} \mathrm{ha}^{-1}$ de $\mathrm{N}, 70 \mathrm{~kg} \mathrm{ha}^{-1}$ de $\mathrm{P}_{2} \mathrm{O}_{5} \mathrm{e}$ $40 \mathrm{~kg} \mathrm{ha}^{-1}$ de $\mathrm{K}_{2} \mathrm{O}$, em dois momentos diferentes: no plantio, $250 \mathrm{~kg} \mathrm{ha}^{-1}$ da fórmula 08-28-16, que forneceu $20 \mathrm{~kg} \mathrm{ha}^{-1} \mathrm{de}$ $\mathrm{N}, 70 \mathrm{~kg} \mathrm{ha}^{-1} \mathrm{de}_{2} \mathrm{P}_{2} \mathrm{O}_{5}$ e $40 \mathrm{~kg} \mathrm{ha}^{-1} \mathrm{~K}_{2} \mathrm{O}$; após 60 dias, foram aplicados $44,4 \mathrm{~kg} \mathrm{ha}^{-1}$ de uréia, que forneceu o restante do nitrogênio necessário, de acordo com a recomendação.

A adubação com o composto celulósico foi realizada mediante sua análise química (Tabela 2) e obedecendo as proporções estabelecidas para a adubação mineral. Sabendo-se que, para obtenção de produtividades elevadas, é necessária a aplicação de $40 \mathrm{~kg} \mathrm{ha}^{-1}$ de $\mathrm{N}, 70 \mathrm{~kg} \mathrm{ha}^{-1} \mathrm{de}_{2} \mathrm{P}_{5}$ e $40 \mathrm{~kg} \mathrm{ha}^{-1} \mathrm{~K}_{2} \mathrm{O}$, citados anteriormente, e que cada 10 toneladas do composto contêm $63 \mathrm{~kg}$ de Nitrogênio (Tabela 1), 54,96 kg de $\mathrm{P}_{2} \mathrm{O}_{5}(24 \mathrm{~kg}$ de $\mathrm{P}$ x 2,29) e 71,41 kg de $\mathrm{K}_{2} \mathrm{O}(59,51 \mathrm{~kg}$ de $\mathrm{Kx} 1,2)$, estipularam-se então as doses de 10,15 e 20 t ha $^{-1}$ do composto.

O composto orgânico foi cedido pela Central de Compostagem do Grupo Ambitec, unidade da International Paper, em Mogi Guaçu, SP, distante $580 \mathrm{~km}$ do local de implantação (Selvíria, MS). Locou-se uma carreta para trazer 30 toneladas desse material, ao custo de R $\$ 3.300,00$, portanto, $\mathrm{R} \$ 110,00$ por tonelada.

No momento de sua aplicação, o composto apresentava umidade de $63,3 \%$ e as doses de 10,15 e $20 \mathrm{t} \mathrm{ha}^{-1}$ foram calculadas a partir de sua massa seca em estufa, a $105^{\circ} \mathrm{C}$, e aplicadas em sulco. Considerando-se $3.334 \mathrm{~m}^{2}$ por ha, conforme o espaçamento de $3 \mathrm{~m}$ entre linhas de plantio aplicaram-se, portanto, 9,08 t de composto úmido, para composição da dose de $10 \mathrm{tha}^{-1} ; 13,62 \mathrm{t}$, para a dose de 15 $\mathrm{t} \mathrm{ha}^{-1}$ e $18,17 \mathrm{t}$, para a dose de $20 \mathrm{t} \mathrm{ha}^{-1}$.

As operações mecanizadas, de aração profunda com arado de disco e sulcação da linha de plantio, foram realizadas com utilização de um trator de pneus 4x4 e $120 \mathrm{cv}$ de potência. As operações de gradagem, calagem, aplicação de herbicida (pulverizador de 600 1), roçagem, transporte de insumos (carreta de 4 t) e rega (tanque de 6000 1) foram realizadas com um trator de pneus $4 \times 2 \mathrm{e}, 75 \mathrm{cv}$ de potência.

\section{RESULTADOS E DISCUSSÃO}

A estimativa do custo de implantação da cultura do eucalipto (Eucalyptus urograndis), considerando-se a adubação mineral, pode ser observada na Tabela 3 . O custo total foi de $\mathrm{R} \$ 3.456,82 \mathrm{ha}^{-1}$. Os gastos com aquisição de mudas para plantio e replantio têm um custo elevado, em relação aos demais itens, representando $18,55 \%$ do custo total. A seguir, a remuneração da terra, conforme o 
Tabela 1. Análise química do Latossolo Vermelho distrófico

\begin{tabular}{|c|c|c|c|c|c|c|c|c|c|c|c|c|}
\hline \multirow{2}{*}{$\begin{array}{l}\text { Camada } \\
(\mathbf{m}) \\
\end{array}$} & \multirow{2}{*}{$\begin{array}{l}\text { P-resina } \\
\text { mg dm }^{-3} \\
\end{array}$} & \multirow{2}{*}{$\begin{array}{c}\text { MO } \\
\text { g dm }^{-3}\end{array}$} & \multirow{2}{*}{$\begin{array}{c}\mathrm{pH} \\
\mathrm{CaCl}_{2}\end{array}$} & $\mathbf{K}$ & $\mathrm{Ca}$ & Mg & $\mathbf{H}+\mathrm{Al}$ & Al & SB & CTC & $\mathbf{V}$ & m \\
\hline & & & & \multicolumn{8}{|c|}{$\mathrm{mmol}_{\mathrm{c}} \mathrm{dm}^{-3}$} & $\%$ \\
\hline $0-0,05$ & 5 & 27 & 5,1 & 2,4 & 10 & 11 & 25 & 0 & 23,4 & 48,4 & 48 & 0 \\
\hline $0,05-0,10$ & 3 & 22 & 4,7 & 1,6 & 8 & 5 & 28 & 2 & 14,6 & 34 & 34 & 12 \\
\hline $0,10-0,20$ & 3 & 19 & 4,8 & 1,1 & 7 & 4 & 26 & 2 & 12,1 & 32 & 32 & 14 \\
\hline $0,20-0,40$ & 3 & 13 & 4,6 & 0,7 & 4 & 2 & 24 & 4 & 6,7 & 22 & 22 & 37 \\
\hline
\end{tabular}

preço médio pago pelo arrendamento, na região, de $\mathrm{R} \$$ 396,70 por hectare, apresentou $11,48 \%$ do custo total. A necessidade de rega, no momento do plantio e aos 15 dias após o estabelecimento das plantas, representou $10,61 \%$ do custo total. Gastos com a adubação mineral (fórmula 08-28-16 + ureia) representaram 11,13\% do COE, 9,87\% do COT e $8,57 \%$ do custo total. A seguir, gastos com mão de obra no plantio representaram $8,10 \%$ do custo total de implantação.

Para a implantação da cultura do eucalipto, utilizandose a adubação mineral, os materiais de consumo representaram a maior percentagem dos custos, totalizando $37,26 \%$ (Figura 1), constituídos pelos fertilizantes e corretivos, herbicida, inseticida e as mudas. Do valor total estimado, 75,12\% correspondem ao custo operacional efetivo. Os valores estimados corroboram os obtidos por Rapassi et al. (2008), em levantamento de custo de implantação de eucalipto no município de Suzanápolis, região oeste do Estado de São Paulo, onde o custo total foi estimado em R $\$ 2.889,50 /$ ha, para o ano de 2007, em que $73 \%$ dos custos referiram-se a gastos com operações e material de consumo (COE).

Os custos de implantação de eucalipto, usando-se 10 $\mathrm{t} \mathrm{ha}^{-1}$ de um composto orgânico advindo da indústria de celulose, podem ser verificados na Tabela 4. Para este plantio, o custo total estimado foi de $\mathrm{R} \$ 4.267,86 \mathrm{ha}^{-1}$ (Tabela 4), superior em R \$ 811,04 ao da implantação com adubação mineral (Tabela 3). As despesas com o transporte do composto foram correspondentes a $23,41 \%$ do custo total, valor elevado, por causa da quantidade e da distância do local de fornecimento $(580 \mathrm{~km})$. Somado a sua aplicação em sulco, com auxílio de trator com carreta, mais mão de obra para descarregar, tem-se um total de $\mathrm{R} \$$ $1.139,54$, representando $34,48 \%$ do COE, $30,75 \%$ do COT e 26,70\% do custo total. Mudas para plantio e replantio, remuneração da terra e regas vieram em seguida, representando, respectivamente, $15,03,9,30$ e $8,60 \%$ do custo total (Tabela 4).

A utilização de $10 \mathrm{t} \mathrm{ha}^{-1}$ desse material representa a maior percentagem dos custos de implantação (Figura 2), seguido pelos materiais de consumo e outros, respectivamente.

A estimativa dos custos de implantação com a dose de 15 t ha $^{-1}$ do composto pode ser observada na Tabela 4.
O custo total determinado foi de $\mathrm{R} \$ 4.879,90 \mathrm{ha}^{-1}$, valor $\mathrm{R} \$$ $1.423,08$, superior ao da implantação com adubação mineral (Tabela 3), e R \$ 612,04 superior ao da dose de $10 \mathrm{t} \mathrm{ha}^{-1}$ (Tabela 4). Como foi verificado, para a utilização de $10 \mathrm{t}$ ha $^{-1}$ de composto, os gastos com o transporte desse material também foram o custo mais representativo da implantação do plantio $(30,71 \%$ do custo total de implantação). Tem-se, também, um maior gasto com sua aplicação mecanizada e uso de três diaristas, trabalhando meio período para sua deposição nos sulcos, representando, portanto, 34,33\% do custo total de implantação da cultura (Figura 3). Os demais itens permaneceram semelhantes à dose de $10 \mathrm{t} \mathrm{ha}^{-1}$.

No plantio utilizando $20 \mathrm{t} \mathrm{ha}^{-1}$ do composto, o custo total foi de $\mathrm{R} \$ 5.472,33 \mathrm{tha}^{-1}$ (Tabela 4). Verifica-se, nova-

Tabela 2. Caracterização química do composto proveniente de resíduos da fabricação de celulose, produzida no município de Mogi Guaçu, SP

\begin{tabular}{lrl}
\hline Parâmetro & & Unidade \\
\hline pH & 9,5 & - \\
Umidade, a 60 - 65 ${ }^{\circ} \mathrm{C}$ & 5,9 & $\%\left(\mathrm{~m} \mathrm{~m}^{-1}\right)$ \\
Carbono orgânico & 186,0 & $\mathrm{~g} \mathrm{~kg}^{-1} \mathrm{de} \mathrm{C}$ \\
Nitrogênio Kjeldahl & 6,3 & $\mathrm{~g} \mathrm{~kg}^{-1} \mathrm{de} \mathrm{N}$ \\
Relação C/N & 29,7 & - \\
Boro & 30,3 & $\mathrm{mg} \mathrm{kg}^{-1} \mathrm{de} \mathrm{B}$ \\
Cálcio & 86,9 & $\mathrm{~g} \mathrm{~kg}^{-1} \mathrm{de} \mathrm{Ca}$ \\
Cobre & 14,3 & $\mathrm{mg} \mathrm{kg}^{-1} \mathrm{de} \mathrm{Cu}$ \\
Enxofre & 1,8 & $\mathrm{~g} \mathrm{~kg}^{-1} \mathrm{de} \mathrm{S}$ \\
Ferro & 5458,0 & $\mathrm{mg} \mathrm{kg}^{-1} \mathrm{de} \mathrm{Fe}$ \\
Fósforo & 2,4 & $\mathrm{~g} \mathrm{~kg}^{-1} \mathrm{de} \mathrm{P}^{-1}$ \\
Magnésio & 3,8 & $\mathrm{~g} \mathrm{~kg}^{-1} \mathrm{de} \mathrm{Mg}^{-1}$ \\
Manganês & 845,0 & $\mathrm{mg} \mathrm{kg}^{-1} \mathrm{de} \mathrm{Mn}$ \\
Potássio & 5951,0 & $\mathrm{mg} \mathrm{kg}^{-1} \mathrm{de} \mathrm{K}$ \\
Zinco & 27,9 & $\mathrm{mg} \mathrm{kg}^{-1} \mathrm{de} \mathrm{Zn}$ \\
Sódio & 1348,0 & $\mathrm{mg} \mathrm{kg}^{-1} \mathrm{de} \mathrm{Na}$ \\
\hline
\end{tabular}

(1) Resultado expresso na amostra em base seca.

Método de ensaio:

Para metais: US-EPA, SW-846, método 3051, com determinação por fotômetro de chama para $\mathrm{Na}$ e $\mathrm{K}$, para os demais metais determinação por ICP-AES;

Para Nitrogênio total: método Kjeldahl;

Para carbono orgânico: digestão com dicromato e determinação volumétrica;

Para umidade: perda de massa a $60^{\circ} \mathrm{C}$;

Para $\mathrm{pH}$, determinação em extrato aquoso na proporção $1: 10$ (resíduo: água). 
mente, aumento proporcional do custo de transporte (36,51 $\%$, em relação ao custo total), com o aumento da dose. Conforme verificado anteriormente, com o aumento da dose há um aumento no tempo de aplicação tratorizada do composto no campo e o uso de quatro diaristas, trabalhando meio período para sua aplicação e, como consequência, um aumento do custo dessas operações, que representam 50,36\% do COE, 45,24\% do COT e 40,16\% do custo total. Outros custos, que envolvem despesas diversas, depreciações e juros, representam 20,24\% do custo total (Figura 4).
Com base nesses resultados, verifica-se que o uso do composto orgânico, quando comparado com o uso de fertilizante mineral, tem um custo de implantação superior e crescente, de acordo com o aumento das doses. Destacam-se, como principais agravantes, o custo de transporte e aplicação, pelo elevado percentual de umidade do material e pela distância do local de origem.

Acredita-se, porém, que, embora mais oneroso, o uso do composto orgânico e a determinação de sua dose ideal além de incrementos na produtividade, contribuam com a melhoria física, química e biológica do solo. Análises

Tabela 3. Estimativa de Custo de Implantação ha-1 (1667 pés) de Eucalipto (Eucalyptus urograndis clone H-17), - adubação mineral

\begin{tabular}{|c|c|c|c|c|}
\hline DESCRIÇÃO & ESPECIF. & QTD. & V. UNIT. (R\$) & TOTAL $(\mathbf{R} \$)$ \\
\hline \multicolumn{5}{|l|}{ A - OPERAÇÕES MECANIZADAS } \\
\hline Aração profunda & $\mathrm{HM}$ & 1,3 & 50,48 & 63,10 \\
\hline Gradagem niveladora & $\mathrm{HM}$ & 0,8 & 46,79 & 37,43 \\
\hline Sulcação linha de Plantio & $\mathrm{HM}$ & 0,8 & 48,61 & 38,89 \\
\hline Calagem & $\mathrm{HM}$ & 0,8 & 46,79 & 37,43 \\
\hline Aplicação de herbicida dirigido & $\mathrm{HM}$ & 1,0 & 52,60 & 52,60 \\
\hline Aplicação de herbicida na linha & $\mathrm{HM}$ & 0,5 & 52,60 & 26,30 \\
\hline Roçada entre linha (2x) & HM & 1,0 & 42,46 & 42,46 \\
\hline Transp. de insumos $(2 \mathrm{x})$ & HM & 1,0 & 43,76 & 43,76 \\
\hline Rega após plantio (2x) & $\mathrm{HM}$ & 8,0 & 45,86 & 366,88 \\
\hline Subtotal A & & & & 708,86 \\
\hline \multicolumn{5}{|l|}{ B - OPERAÇÕES MANUAIS } \\
\hline Adubação de plantio & HD & 1,5 & 40,00 & 60,00 \\
\hline Controle de formigas & HD & 2,0 & 40,00 & 80,00 \\
\hline Plantio & HD & 7,0 & 40,00 & 280,00 \\
\hline Replantio & HD & 2,0 & 40,00 & 80,00 \\
\hline Adubação de cobertura & HD & 1,5 & 40,00 & 60,00 \\
\hline Herbicida dirigido & HD & 1,0 & 40,00 & 40,00 \\
\hline Subtotal B & & & & 600,00 \\
\hline \multicolumn{5}{|l|}{ C - MATERIAL } \\
\hline Fertilizante 8- 28 - 16 & $\mathrm{t}$ & 0,3 & 940,00 & 235,00 \\
\hline Fertilizante ureia & $\mathrm{kg}$ & 44,4 & 1,22 & 54,17 \\
\hline Herbicida Oxyfluorfen & 1 & 4,0 & 46,70 & 186,80 \\
\hline Herbicida Glifosato & 1 & 6,0 & 10,00 & 60,00 \\
\hline Inseticida formicida Fipronil & $\mathrm{kg}$ & 0,1 & 610,00 & 30,50 \\
\hline Calcário & $\mathrm{t}$ & 1,0 & 80,00 & 80,00 \\
\hline Mudas plantio e replantio (10\%) & unid & 1832,6 & 0,35 & 641,41 \\
\hline Subtotal C & & & & $1.287,88$ \\
\hline Custo operacional efetivo (COE) & & & & $2.596,73$ \\
\hline Outras despesas & & & & 129,84 \\
\hline Depreciação de máquinas e equip. & & & & 116,07 \\
\hline Juros de custeio & & & & 87,64 \\
\hline Custo operacional total (COT) & & & & $2.930,28$ \\
\hline Remuneração da terra & & & & 396,70 \\
\hline Outros custos fixos & & & & 129,84 \\
\hline CUSTO TOTAL & & & & $3.456,82$ \\
\hline
\end{tabular}

Fonte: Dados da Pesquisa.

Rev. Ceres, Viçosa, v. 58, n.5, p. 576-583, set/out, 2011 
dendrométricas preliminares demonstraram que as doses de 15 e de $20 \mathrm{t} \mathrm{ha}^{-1}$ proporcionaram crescimento em altura e diâmetro de caule, tão significativo quanto o obtido com a adubação mineral, os resultados de ambos os tratamentos não diferindo entre si.
Os resíduos de lodo de esgoto, indústria de papel e celulose, lixo urbano e esterco animal vêm sendo utilizados e amplamente estudados como adubo orgânico, de modo que seu aproveitamento em plantações florestais parece ser uma das opções mais indicadas, sob os aspec-

Tabela 4. Estimativa de Custo de Implantação ha-1 (1667 pés) de Eucalipto (Eucalyptus urograndis clone H-17), composto doses 10, 15 e 20 t ha $^{-1}$

\begin{tabular}{|c|c|c|c|c|c|c|}
\hline \multirow{2}{*}{$\begin{array}{l}\text { DESCRIÇÃO } \\
\text { A - OPERAÇÕES MECANIZADA }\end{array}$} & \multicolumn{2}{|l|}{ ESPECIF. } & QTD. & \multicolumn{2}{|l|}{ V. UNIT(R\$) } & TOTAL (R\$) \\
\hline & & & & & & \\
\hline Aração profunda & $\mathrm{HM}$ & & 1,3 & 50,48 & & 63,10 \\
\hline gradagem niveladora & $\mathrm{HM}$ & & 0,8 & 46,79 & & 37,43 \\
\hline Sulcos de plantio & $\mathrm{HM}$ & & 0,8 & 48,61 & & 38,89 \\
\hline Calagem & $\mathrm{HM}$ & & 0,8 & 46,79 & & 37,43 \\
\hline Aplicação de herbicida dirigido & $\mathrm{HM}$ & & 1,0 & 52,60 & & 52,60 \\
\hline Aplicação de herbicida na linha & $\mathrm{HM}$ & & 0,5 & 52,60 & & 26,30 \\
\hline Roçada entre linha $(2 \mathrm{x})$ & $\mathrm{HM}$ & & 1 & 42,46 & & 42,46 \\
\hline Transp. de insumos $(1 \mathrm{x})$ & $\mathrm{HM}$ & & 0,5 & 43,76 & & 21,88 \\
\hline Rega após plantio $(2 \mathrm{x})$ & $\mathrm{HM}$ & & 8,0 & 45,86 & & 366,88 \\
\hline Subtotal A & & & & & & 686,98 \\
\hline \multicolumn{7}{|l|}{ B - OPERAÇÕES MANUAIS } \\
\hline Controle de formigas & HD & & 2,0 & 40,00 & & 80,00 \\
\hline Plantio & HD & & 7,0 & 40,00 & & 280,00 \\
\hline Replantio & HD & & 2,0 & 40,00 & & 80,00 \\
\hline Herbicida dirigido & HD & & 1,0 & 40,00 & & 40,00 \\
\hline Subtotal B & & & & & & 480,00 \\
\hline \multicolumn{7}{|l|}{ C - MATERIAL } \\
\hline Herbicida Oxyfluorfen & 1 & & 4,0 & 46,70 & & 186,80 \\
\hline Herbicida Glifosato & 1 & & 6,0 & 10,00 & & 60,00 \\
\hline Inseticida formicida Fipronil & $\mathrm{kg}$ & & 0,1 & 610,00 & & 30,50 \\
\hline Calcário & ton & & 1,0 & 80,00 & & 80,00 \\
\hline Mudas plantio e replantio (10\%) & unid & & 1832,6 & 0,35 & & 641,41 \\
\hline Subtotal C & & & & & & 998,71 \\
\hline DESCRIÇÃO & ESPECIF. & QTD. & V. UNIT(R\$) & & TOTAL (I & R\$) \\
\hline D - COMPOSTO & & & & $10 \mathrm{t} \mathrm{ha}^{-1}$ & 15 ha $^{-1}$ & $20 \mathrm{t} \mathrm{ha}^{-1}$ \\
\hline \multicolumn{7}{|l|}{ Dose10t ha ${ }^{-1}$} \\
\hline Transporte & ton & 9,1 & 110,00 & 999,02 & - & - \\
\hline Aplicação do composto & HD & 1,5 & 40,00 & 60,00 & - & - \\
\hline Aplicação do composto & $\mathrm{HM}$ & 1,8 & 43,76 & 80,52 & - & - \\
\hline \multicolumn{7}{|l|}{ Dose $15 \mathrm{t} \mathrm{ha}^{-1}$} \\
\hline Transporte & ton & 13,6 & 110,00 & - & 1498,53 & - \\
\hline Aplicação do composto & HD & 1,5 & 40,00 & - & 60,00 & - \\
\hline \multicolumn{7}{|l|}{ Dose $20 \mathrm{tha}^{-1}$} \\
\hline Transporte & ton & 18,2 & 110,00 & - & - & 1998,15 \\
\hline Aplicação do composto & HD & 2 & 40,00 & - & - & 80,00 \\
\hline Aplicação do composto & $\mathrm{HM}$ & 2,7 & 43,76 & - & - & 119,46 \\
\hline Subtotal D & & & & 1139,54 & 1675,37 & 2197,61 \\
\hline Custo operacional efetivo (COE) & & & & 3305,22 & 3841,05 & 4363,30 \\
\hline Outras despesas & & & & 165,26 & 192,05 & 218,17 \\
\hline Depreciação de máquinas e equip. & & & & 123,86 & 128,40 & 128,74 \\
\hline Juros de custeio & & & & 111,55 & 129,64 & 147,26 \\
\hline Custo operacional total (COT) & & & & 3705,90 & 4291,14 & 4857,47 \\
\hline Remuneração da terra & & & & 396,70 & 396,70 & 396,70 \\
\hline Outros custos fixos & & & & 165,26 & 192,05 & 218,17 \\
\hline CUSTO TOTAL & & & & 4267,86 & 4879,90 & 5472,33 \\
\hline
\end{tabular}

Fonte: Dados da Pesquisa. 


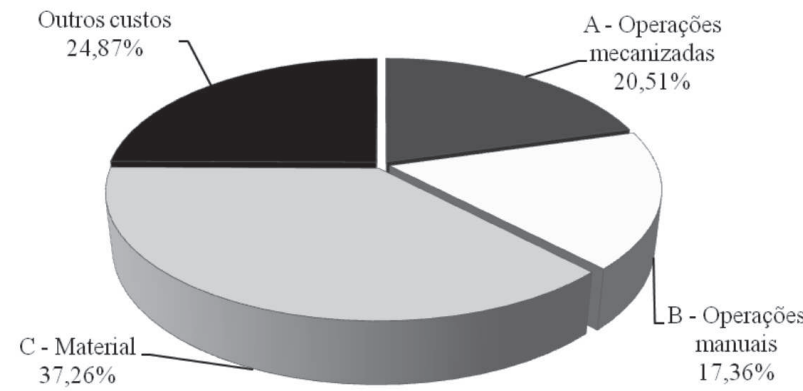

Figura 1. Distribuição percentual da Estimativa de Custo de implantação de Eucalipto (Eucalyptus urograndis clone $\mathrm{H}$-17), com adubação mineral.

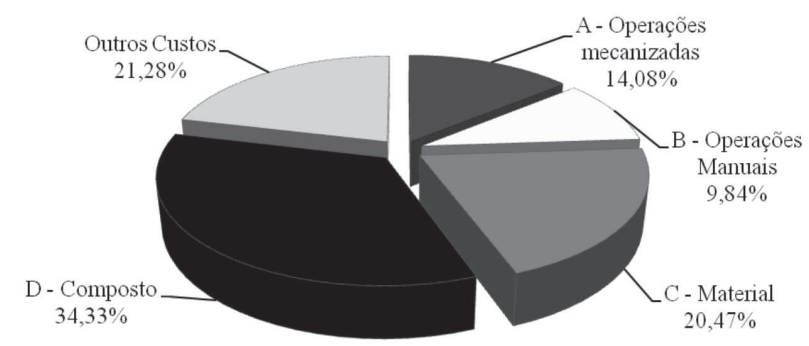

Figura 3. Distribuição percentual da Estimativa de Custo de implantação (\%) de Eucalipto (Eucalyptus urograndis clone $\mathrm{H}$ 17), com 15 t ha $^{-1}$ do composto orgânico.

tos sanitário, ambiental, silvicultural, social e econômico, devendo seu uso ser realizado de maneira cuidadosa, de modo a não provocar danos ao ambiente (Figueiredo \& Tanamati, 2010).

De acordo com Abreu Júnior et al. (2005), o uso de resíduos orgânicos para fins agrícolas é, econômica e ambientalmente, mais sustentável, em médio e longo prazos, do que a incineração e disposição em lixões, corpos d'água e aterros, desde que se considerem a disponibilidade e os custos de transporte e da aplicação do resíduo na área agrícola.

Com a chegada de novas indústrias do setor de papel e celulose para região em estudo (Selvíria, MS), resíduos também serão produzidos e sua utilização pode vir a se tornar viável em locais próximos às unidades produtoras. Nesse sentido, considerando-se apenas os gastos com os fertilizantes utilizados na pesquisa (Tabela 3) e o custo de transporte do composto por tonelada aplicada (Tabela 4), estima-se que sa utilização da dose de 10 tha $^{-1}$, seria viável economicamente somente a distâncias inferiores a $168 \mathrm{~km}$. A utilização da dose de 15 t ha ${ }^{-1}$ é viável até à distância máxima de $112 \mathrm{~km}$, ao redor da fonte de origem. A aplicação de $20 \mathrm{tha}^{-1}$ desse composto é viável economicamente até a $84 \mathrm{~km}$ da unidade produtora. Menores gastos com transporte serão obtidos quanto menor a distância entre local de produção e aplicação e menor o teor de umidade presente no composto.



Figura 2. Distribuição percentual da Estimativa de Custo de implantação (\%) de Eucalipto (Eucalyptus urograndis clone $\mathrm{H}$ 17), com 10 t ha ${ }^{-1}$ do composto orgânico

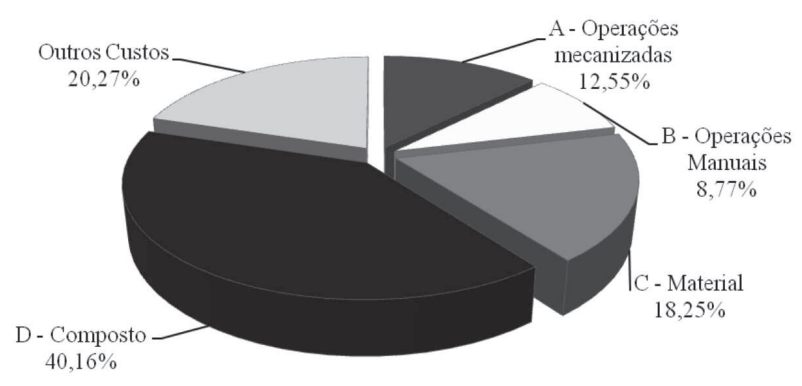

Figura 4. Distribuição percentual da Estimativa de Custo de implantação (\%) de Eucalipto (Eucalyptus urograndis clone $\mathrm{H}$ 17), com 20 t ha ${ }^{-1}$ do composto orgânico.

\section{CONCLUSÕES}

$\mathrm{Na}$ implantação da cultura do eucalipto, a utilização do composto orgânico, oriundo de resíduos da indústria de celulose, mostrou-se mais onerosa que a adubação mineral, por causa do alto custo do transporte, neste estudo, a distância foi de $580 \mathrm{~km}$.

A despesa com o transporte destacou-se e, no caso da utilização da menor dose de composto orgânico (10 t $\mathrm{ha}^{-1}$ ), representou $30 \%$ do custo operacional efetivo. Somente em distância média inferior a $168 \mathrm{~km}$ tornar-se-ia viável, economicamente, o uso do composto, quando comparado com o do fertilizante mineral.

A instalação de uma indústria do setor de papel e celulose, na região em estudo (Selvíria, MS), viabilizará aplicações de doses de composto celulósico na cultura do eucalipto.

\section{REFERÊNCIAS}

Abreu Junior CH, Boaretto AE, Muraoka T \& Kiehl JC (2005) Uso agrícola de resíduos orgânicos potencialmente poluentes: propriedades químicas do solo e produção vegetal. Tópicos Ciência do Solo, 4:391-470.

Albuquerque JA, Argenton J, Fontana EC, Costa FS \& Rech TD (2002) Propriedades físicas e químicas de solos incubados com resíduo alcalino da indústria de celulose. Revista Brasileira de Ciência do Solo, 4:1065-1073.

Almeida ICC (2008) Atributos físicos do solo em resposta à adição de efluente tratado de indústria de celulose. Dissertação de Mestrado. Universidade Federal de Viçosa, Viçosa. 68p. 
Andrade GC, Silva HD, Bellote AFJ \& Ferreira CA (2003) Efeitos da adubação fosfatada e da aplicação de resíduo de celulose no crescimento de Eucalyptus dunnii. Boletim de Pesquisa Florestal, Colombo, 47:43-54.

Barretto VCM (2008) Resíduos de indústria de celulose e papel na fertilidade do solo e no desenvolvimento de eucalipto. 2008. Tese de doutorado. Universidade Estadual Paulista, Faculdade de Ciências Agrárias e Veterinárias, Jaboticabal. 64p.

Bellote AFJ, Silva HD, Ferreira CA \& Andrade GC (1998) Resíduos da indústria de celulose em plantios florestais. Boletim de Pesquisa Florestal, Colombo, 37:99-106.

BRACELPA - Associação Brasileira de Papel e Celulose (2009) Relatório anual 2008/2009. Disponível em: <http:// www.sbs.org.br/relatoriosbs2009.pdf>. Acessado em: 24 de setembro de 2010

CONAB - Companhia Nacional de Abastecimento (2010) Custos de Produção Agrícola: A metodologia da Conab. Brasília, CONAB. 60 p.

Demattê JLI (1980) Levantamento detalhado dos solos do Campus Experimental de Ilha Solteira. Piracicaba, 131p. Não Publicado.

EMBRAPA - Empresa Brasileira de Pesquisa Agropecuária. EMBRAPA Solos (2006). Ministério da Agricultura, Pecuária e Abastecimento. Sistema Brasileiro de Classificação de Solos. 2ed. Rio de Janeiro, EMBRAPA. 306p.

Figueiredo PG \& Tanamati FY (2010) Adubação orgânica e contaminação ambiental. Revista Verde De Agroecologia D Desenvolvimento Sustentável Grupo Verde De Agricultura Alternativa, $5: 1-4$

Guerra MASL (2007) Avaliação de indicadores biológicos e físicoquímicos no composto orgânico produzido a partir de resíduos da indústria de celulose. Dissertação de Mestrado. Universidade Federal de Viçosa, Viçosa. 61p.
Guerrini IA \& Moro L (1994) Influência da aplicação de resíduos industriais de fábrica de celulose e papel em plantios de eucalipto: efeitos no solo e na planta. In: Seminário sobre resíduos industriais e urbanos em florestas, Botucatu. Anais, Faculdade de Ciências Agronômicas. p.188-215.

Martin NB, Serra R, Oliveira MDM, Angelo JA \& Okawa H (1998) Sistema integrado de custos agropecuários - CUSTAGRI. Informações Econômicas, 28:7-28.

Matsunaga M, Bemelmans PF \& Toledo PEN (1976) Metodologia de custo de produção utilizado pelo IEA. Agricultura em São Paulo, 23:123-139.

Raij BV, Cantarella H, Quaggio JA \& Furlani AMC (1997) Recomendações de adubação e calagem para o estado de São Paulo. Campinas. 285p. (Boletim Técnico, 100).

Rapassi RMA, Tarsitano MAA, Pereira JCR, \& Araujo CAM (2008) Cultura do eucalipto na região de Suzanápolis, Estado de São Paulo: análise econômica. Informações econômicas, 38:4.

Rodrigues CM (2004) Efeito da aplicação de resíduo da indústria de papel e celulose nos atributos químicos, físicos e biológicos do solo, na nutrição e biomassa do Pinus taeda L. Dissertação de Mestrado. Universidade Federal do Paraná, Curitiba. 109p.

Sociedade Brasileira de Silvicultura (2008) Fatos e números do Brasil Florestal. 93p. Disponível em: http://www.sbs.org.br/ FatoseNumerosdoBrasilFlorestal.pdf Acessado em: 24 de setembro de 2010.

Sociedade brasileira de Silvicultura (2009). Relatório de atividades 2009. 11 p. Disponível em: http://www.sbs.org.br/ relatoriosbs2009.pdf. Acessado em: 24 de setembro de 2010. 